\title{
Digital Monitoring Experience in Digital Media and the Internet
}

\author{
$1^{\text {st }}$ Annisa Reginasari* \\ Faculty of Psychology \\ Universitas Gadjah Mada \\ Yogyakarta, Indonesia \\ annisa.reginasari@mail.ugm.ac.id \\ $3^{\text {rd }}$ Bhina Patria \\ Faculty of Psychology \\ Universitas Gadjah Mado \\ Yogyakarta, Indonesia \\ patria@ugm.ac.id
}

\author{
$2^{\text {nd }}$ Tina Afiatin \\ Faculty of Psychology \\ Universitas Gadjah Mada \\ Yogyakarta, Indonesia \\ afiatin04@ugm.ac.id
}

\author{
$4^{\text {th }}$ Kokom Komariah \\ Department of Family Welfare Education \\ Universitas Negeri Yogyakarta \\ Yogyakarta, Indonesia \\ kokom@uny.ac.id
}

\begin{abstract}
Nowadays, parents face the challenge related to social media use problems of their children, as the internet and related technology is more advance than previous days. Nevertheless, the young generation is enthusiastic about digital technology. The paradox of internet use in young and older generations has a different meaning as it widens the digital literacy gap. This study aimed to explore digital monitoring on the experiences of 123 participants. They were divided into four focus groups based on the stages of family development i.e. a group of single and new couples $(n=54)$, a group of families with children aged 0-6 years $(n=24)$, a group of families with children aged 7-11 years $(n=26)$, and a group of families with children over 11 years old $(n=29)$. There were 17 participants actively giving their thoughts, feelings, and experiences to focus group discussions within two hours of conversations. Using the Grounded Theory method and MAXQDA assistance of the 2018 version, we categorized themes based on 571 code systems. The topics discussed were digital monitoring strategies, digital paradoxes, digital parenting, role synergy, experiential learning supported digitally, and privacy. The contribution of this research to digital monitoring theories is the exploration of participants' contextual experiences.
\end{abstract}

Keywords - digital literacy, focused group discussion, parental monitoring, family development

\section{INTRODUCTION}

Parents experienced the multi-use of the internet, with multiple devices, that likely hard to manage. Nevertheless, the young generation is enthusiastic about digital movement. The paradox of internet use in young and older generations has a different meaning as it widens the digital literacy gap. Prensky [1] stated there are two different cohorts related to technology. The first is digital native, as a generation born in the world of new media (Computer games, e-mail, the Internet, cell phones), consume information promptly, tend to like the parallel process and multi-tasking. Whereas digital immigrants refer to older generations who are more familiar with old media (newspapers, television), tend to like the step-by-step process, and do one thing at a time. Parents and youths experience different emotions when it comes to the media [2]. While parents feel anxious about how social networks and websites give greater freedom (i.e., extra probabilities for risk and connections to unknown others), youths feel completely satisfied with how media provide them with the freedom. The incongruity of the experience of involvement in social media and the internet among parents and children creates emotional disparities [3]. Nikken [4] suggested that it is necessary to discuss how parents' personal digital experiences and their digital media use capacity provide adequate supervision to their children. Parents with a few experiences in using social media tend to recognize that digital monitoring is more challenging to be implemented as their parenting practices. Therefore, this study aimed to explore parents' experiences of using social media and the internet and practicing digital monitoring to their children and other members of the family.

\section{THEORETICAL FRAMEWORK}

\section{A. Parental Monitoring}

Parental monitoring has become a growing theme of research in the fields of psychology, communication, and parenting. As parents attempt to discover children's activities and whereabouts [5], parental monitoring needs to track and structure the physical and social environment [6]. The control component in parental monitoring is emphasized because it pays obeisance to parents' authority of the function and role in parenting behavior. However, the concept of parental monitoring likewise considers the child's intentional disclosure of their agenda to parents [7].

Technological advancements influenced previous researchers to redefine the concept and theory of parental monitoring. In parental mediation terms, Valkenburg et al. [8] proposed a television mediation construct consisting of instructive mediation, restrictive, and social mediation. Parental mediation concept posits that mother and father use one-of-a-kind interpersonal conversation techniques in their efforts to mediate and mitigate the damaging results of the media in their children's lives [2]. As social agents in value internalizing, parents have the chance to create an ideal interpersonal interaction with their children (or youth) in cyberspace before they face the real internet society [2], [9], [10]. 
Parental monitoring is expressed differently depending on the type of technology in which each family member interacts. Parents can still read the newspaper while supervising children do their homework or other activity. However, in digital and internet monitoring, parents' strategy of accompanying children who are entering the online world (i.e., co-use strategies are increasingly active, for conversations about online activities) is more likely challenging to occur. Parents cannot be convinced about what children view on a limited or small screen (e.g., PC, smartphone). The parent-child interaction related to internet and social media use affected not only of time and place but also the chronosystem (i.e., a child's life, sociohistorical events) [11].

\section{B. Experiential Learning}

Experiential learning theory postulates that learning is abstract knowledge resulted from transformations of understanding contextual experience [12]. Four experiential learning cycles explain the step of new learning acquisition based on real-life events, that is, concrete experience, reflective observation, abstract conceptualization, and active experimentation. The previous study showed that the proposed experiential learning approach effectively enhanced students' learning motivation, deep learning strategy, and acceptance of the technology [13] Participating in social media and the internet becomes an alternative way for parents and children to spend their quality time and also to acquire new interactive experiences together.

\section{Methodology}

\section{A. Participants}

Of the 123 participants who joined the discussion, there were 17 participants actively giving their thoughts, feelings, and experiences in social media and the internet. They were categorized into four groups of family [14], i.e. single and new married couples $(n=54)$, family with children aged $0-6$ years $(n=24)$, family with children aged 7-11 years $(n=$ $26)$, and family with children aged over 11 years old $(\mathrm{n}=$ 29). Informed consents were given to obtain their approvals to join the study.

\section{B. Instruments and Data Collecting Method}

Focus group discussions were conducted to explore the participants' experiences of using social media and the internet. The discussions were set up in four different rooms and recorded using a voice recorder, one for each room. Each focused group discussion was led by a moderator and noted by a note-taker. The moderators were provided with the same set of discussion question guides. The participants were asked to respond to questions such as "How was your experience in using social media and the internet? How about a memorable experience when searching for information on the internet? How do you participate in the use of digital technology by your children or other family members? How do you limit your children or family members' use of the internet? How do you assist your children and family members in accessing the information on the internet?"

\section{Data Analysis Method}

This study used a qualitative approach, involving a Grounded Theory analysis [15]. Data collected was analyzed by MAXQDA version 2018 to build a code system. We discovered 571 meaning segmentation or code systems and then grouped them into 12 categories that were discussed by the participants.

\section{RESULTS AND DISCUSSION}

\section{A. Digital Monitoring Strategies}

Digital monitoring strategies consist of openness, restrictions, participation, storytelling-discussion, and environmental structuring. The participants also talked about the difficulties of implementing ideal digital monitoring.

\section{1) Openness monitoring strategy}

The monitoring strategy that involves openness consists of an agreement and commitment component, trust in the child as well as an appreciation for the child's openness of digital experiences. The agreement was defined how family members, especially among children-parents, carry out negotiations (push-and-pull) regarding the rules of cell phone use. A compromise also must be relinquished among husband and wife about the use of cell phones when they spend time together with children. Parents may enforce the consequences of the agreement that has been built together by the values adopted by the family. The agreement needs to be reached due to it possibly create a balance in family relation quality.

"There are agreements such as the reward and punishment system. Okay [kid,] you can see [the content] 15 or 30 minutes but accompanied. Now you can only see what? Yes, videos on Facebook, funny videos. "- G2, 152

"So if there is an agreed hour to study together, repeat what [agreement screen time] is in school, yes we agree." - G2, 158

Family members also need to strive for consistency in enforcing consequences in rule-breaking behavior.

"So it must be consistent so. When we say no to children, yes, we really shouldn't. When we are at half-past 9 all gadgets must turn off, the lights must turn off, and we are ready to sleep, yes it must be done at $8: 30 \mathrm{pm}$. When the child sleeps, after that, we will be fine playing gadgets."G2, 239.

Parents are required to be consistent in upholding the consequences associated with children trust in them. When parents are inconsistent in giving consequences, the child will become confused about the family rules regarding internet use, and then children become resistant to the rules. Children's resistance creates mistrust in parents. Parents recognize that consistency is a challenge in monitoring strategy. Parents need to grant trust to their children. Trust in this context is defined as the degree of parent's confidence that their children has achieved sufficient competence and has entered the appropriate age to decide for him/herself the right action in interacting within the cyber world. Parents believe that their children's skills and abilities are optimized through interactions with digital media and the internet. 
Parents tend to not force children to continue studying and doing some school homework, especially when children are bored, and they want to access entertainment information on the Internet. The element of appreciation for openness occurs when parents provide children with computer facilities at home to access the internet to download education-supporting materials. Children are allowed to access YouTube Kids, and even to play games online (children aged 7-11 years old). Parents identify that the children will be bored by themself playing the online game for a certain amount of time, and then they will stop playing as they obey the agreed limits and consequences.

2) Restriction monitoring strategy

The restriction monitoring is the strategy of limiting the internet use, especially in term of the duration. The restriction is applied in reducing the frequency of usage and internet access (e.g., the cell phone is not considered as a child's private belonging, but rather as the belongings borrowed from their parents; restrictions on internet/WIFI subscription fees).

Parents also discuss restriction strategies to create habituation for children's activities. The restriction strategy emphasizes on the importance of a control approach in digital monitoring of children's activities. Assertiveness is considered as the core topic in supervising children's digital activities because it contains control functions. Control functions can be reached by endorsing warnings, rules, or strict parenting strategies. Warnings and rules must not be endangered to the children, hence parents also need to choose kind words that flourish the child's psychological development.

3) Participatory monitoring strategy

The participatory monitoring strategy is the interaction of parents and children and older family members as role models for children's digital activities.

"Because parents are role models [for their child], they must first be tutored [digital literacy capabilities]." - G2, 353

"The children are imitating their parents [behavior]. So, whether consciously or unconsciously, children will see the action of their parents. When their parents [send a message] to the family group [to] boast, they [the child] can also do that to their friends. "-G1.26

Interaction is considered to be adequately achieved when parents supervise children indirectly (without the knowledge of children), or build involvement in social media groups (e.g., WhatsApp). The objective of this interaction is to encourage children to achieve wise decisions when responding to information in the digital world and the internet. Children can act as an expert to help their parents understand about techniques of mastering internet and social media features within the interactive activity together.

"Moderator: anyone helps you [in understanding features on social media]? Participant: yes, [I was taught by older children]"-G3, 54

"Participant: [My email account' password] was registered by my kid. Moderator: oh, really? Participant: [Yes,] I only need to use it"-G3, 59-61

\section{4) Storytelling and discussion monitoring strategy}

Families with teenager express storytelling and discussion monitoring strategies. These strategies are related to democratic parenting due to enabling children to apply reflective thinking through story-based interaction. Parents talk about challenges in implementing the ideal monitoring. Challenges appear when a monitoring strategy is believed ineffective, such as monitoring in adolescents, parents are less assertive and less consistent; for example, parents have problems in understanding technical terms in accessing social media.

5) Monitoring strategy by structuring media locations

Parents structure the environment where the best place to install a personal computer set and internet device that are easy to observe when children interact with the cyber world or other people in the cyber world.

"The strategy is that a computer screen is placed in the living room so that anyone can monitor it. If, for example, kid opens inappropriate, he will definitely get caught. He can't dodge going to his room"-G3, 38

\section{B. Digital paradoxes}

1) The benefits of social media and the internet

Parents are aware that now they are facing the acceleration of technology. On the other hand, the digital world is so close to the daily basis of the younger generation. The participants explained that the development of features on various social media platforms is changing rapidly. The platforms that used to be popular gradually are abandoned by users who switch to other social media platforms-for example, the features on Facebook as its initial release is different from the current features. The users of WhatsApp application need to follow the latest settings; for example, WhatsApp provides an automatic download feature of each attachment sent (or not automatically), depending on user needs. The participants in the discussion addressed that, together with rapid changes, the internet also offers opportunities and challenges. The opportunities arise from the benefits of the internet for various lines of life.

Digital media and the internet provide chances to access knowledge and information and boost creativity (e.g., create a vlog or video blog, draw animations). It supports learning experiences (e.g., facilitating the talent to design graphics, computer-mediated exams, and facilities to help accompany children to learn), access to health information, and create economic opportunities (e.g., trading). Because of the benefit of efficiency in its facilities and features, the internet can also encourage a positive mood (e.g., entertainment and recreation) and endorse for self-publication (e.g., watching YouTube, playing games).

2) Variation of social media and the internet's benefit for the human being

In perceiving the benefits of social media and the internet, the participants expressed the existence of a personal dilemma. For instance, the use of WhatsApp will depend on how the individual views the practicality of computer-mediated communication. Online chat is 
perceived as an alternative way to fulfil the needs of recreation, information, and economy. Moreover, the internet is recognized as a space for one to escape from any displeasure in the real world.

What is the primary purpose of accessing the information on the internet? Is it for recreational purpose or the information itself? How should the user limit conversations in WhatsApp groups? A solution suggested by the participants was, for example, enforcing restrictions and rules to the online group member. However, the rules will create rigid chat interactions among them. What is the right way to communicate an appreciation to friends in an online group chat? This dilemma was revealed because the participants considered appreciation in different ways. What is the best way to express disapproval? These questions were raised regarding the various subjective purposes of internet use.

3) The challenge of dealing with the cyber world

The challenges faced are deviant online behaviors, such as exposure to the threats by strangers, cyberbullying, internet addiction, and the phenomenon of Fear of Missing Out, the deterioration in physical and physiological health due to excessive internet use. Families can also face negative internet interactions; for example, family members in a WhatsApp group being affected by false news (hoaxes), husband and wife fighting about social media involvement, and parents completely replacing their parental roles and functioning to digital media devices in providing care for children.

The psychological burden due to information overload (e.g., time spent on weekends to work/demands of work through WhatsApp group) tend to affect single and new married couple group. A digital footprint can be used as a material that can be misused to threaten and intimidate victims related to cybercrime. This digital footprint tends to be eternal in the cyber world, and it is difficult to erase, therefore creating a more notable destructive psychological effect on the victim. As a consequence of illegal personal data mining, cybercrimes can also develop as fake news, hoaxes, fake identities, and pornography.

\section{4) Digital gap}

Another dilemma discussed was how the digital divide occurs between cohorts of generations [1]. The digital immigrant cohorts accept that they can keep up with technology, use it well, and become more familiar with social media. This idea is supported by the notion that even the digital immigrant cohort is more open to new experiences (willing to learn). On the other hand, the participants also considered that the immigrant digital generation cohort was not so attached to technology and had difficulty filtering content. Meanwhile, the digital natively cohort tend to like exploring new information from the internet, even they are inseparable from social media. Even though they are still looking for information in books, they are more likely to access information using browsers and search engines on the internet.

\section{Digital literacy}

\section{1) Parent's digital techniques and content literacy}

Similar to digital monitoring with role model strategies, parents also need to understand how the process of finding information takes place on the internet and social media in terms of technical and content aspects. Parents need to have the ability to memorize, choose, and determine the terms, icons, and functions of the features of the internet and social media. It is also essential for parents to connect children's devices to parents' digital devices, for example, by applying multiscreen and sharing passwords code. Parents also choose information content that children may or may not access.

Awareness of digital literacy skills is included in optimizing children's abilities as "editors" of their activities in cyberspace. We named this ability as a review and editing function. This capability requires the ability to comprehend the features of social media, have critical and logical thinking, evaluate contents, compare (between digital and non-digital), cross-check, and filter information.

\section{2) Prepare children's digital literacy}

Parents should be aware of the importance of introducing digital literacy to their children. Awareness grows through teaching the ethical use of digital and social media platforms to children. The ethics of digital use are introduced in family and school environments through socializing a set of flexible rules and consequences. Children must be aware that digital footprints they post in social media have a consequence on their future career opportunities as the posting text, photo, or video could somehow represent themselves. The purpose of introducing digital literacy is to make children able to control themselves and to avoid the negative side of the internet.

3) The contextual digital literacy

Socialization of digital literacy to the family members needs to consider more the contextual circumstances. The context and situation include background, age group, developmental tasks, and even the emotional condition and children's capacity to learn new knowledge.

4) Children's autonomy in cyberspace through digital literacy

Parents need to facilitate children's autonomy, empathy (cognitive and affective), and critical thinking in cyberspace. It is essential to teach that digital footprints left on the internet tend to be eternal, which will affect self-evaluation-for example, using maps to hone children's spatial (cognitive ability).

\section{Parenting Practices}

The elements of parenting discussed by parents are consistency, parenting, and sex education in adolescents, parent-child closeness, habituation, the flexibility of parental roles, and openness to psychological needs. Creating closeness with children is a critical issue in family relationship. Closeness is created when parents and children mutually meet each other's needs for love and becomes a safe and comfortable place to share. 
Parents are expected to understand the basic things the child likes and be able to provide positive guidance. Parents also need to identify other aspects of psychological needs that are relevant to the modern era.

Another element of parenting is about structuring children's habituation. In younger children (e.g., 0-5 years old), harmful internet exposure tends to be preventable if parents begin to structure positive children's habits from the beginning of the developmental task. Children gradually learn about the logic of utilizing the resources they have, which can be limited by external restrictions. Habit encourages children to be able to move from one activity to other activities so that a healthy lifestyle continues by itself (automatically) over time.

The participants' challenge in implementing a parental monitoring strategy was how to manage consistency and to enforce consequences of agreement concerning internet use. The consistency in sustaining discipline was viewed as parents' authority. Parental discipline inconsistency tends to make children hesitate to predict behavior sequences, to develop distrust, and to lead to breaking the rules agreed together. Parents' role flexibility was described as the parental behavior that reflects continuity in observing and learning about children's behavior to meet their basic physical and psychological needs. Collaborations between family (nuclear and extended family), school, and community (neighbourhood) are highlighted in achieving optimal digital monitoring. The most talked-about collaboration type is the synergy between home/family with the school subsystem.

E. The synergy between family, school and community roles

Collaborations between family (nuclear and extended family), school, and community (neighborhood) are highlighted in achieving optimal digital monitoring. The synergy between home/family with the school subsystem was the most frequent theme mentioned by participants. Even though it is challenging for parents, the collaboration should be maintained in creating harmony either to the family or to the school. The consistency of digital monitoring is achieved through an agreement between parents and teachers. A learning mechanism that encourages the use of technology is viewed as school support for digital monitoring strategy. School also involves an application-based mechanism for the selection of student council leaders and supports a gamemaking competition. The mutuality-reciprocal synergy between different generation cohorts, especially in optimizing the benefits of technology, will create innovation. Collaborative digital monitoring also requires the role of a broader social environment, such as neighbors or communities, especially for adolescents.

F. Advising

A digital monitoring strategy by advising is an attempt by parents (or older family members) to explain and frequently remind about the consequences of using digital media and the internet, especially negative consequences to children or younger family members.
Advising strategies relate to the values adopted by a family, school, and cultural settings. Religious or spiritual value emphasizes on the consequences of responsible behavior on the internet use. Parents explain why children are prohibited from accessing harmful content on the internet (e.g., violent game online, pornographic content, internet addiction). Harmful internet contents usually contradict with the norms, values, and culture in society, as well as become perils to their psychological well-being.

"Then I remind my kid 'Remember, if you watch pornography, the pleasure you get will make you addicted. One time watch, tomorrow will access again. Once you continue to become addicted, you will be damaged. I repeat that to my child, so he can remember. So, that ... he is in the 3rd grade of middle school, now he is in 3rd grade of high school, I keep repeating. I think we give understanding according to his age level. We must be wise as parents in providing instruction to children."- G4, 50-53

\section{G. Experiential learning supported by technology}

A unique theme that emerged from the discussions with single and new married couple group was how digital media and the internet could optimize experience-based learning. The internet is still viewed as inadequate to replace individual processes of learning skills as they proceed in the real world. Technology provides the speed of access to information so that the users tend to gain knowledge instantly, yet it can ignore the process of learning experiences through more intense involvement and interaction with the actual problem in real life. Learning practiced directly in the real world tend to be more useful to shape skill. Simulation alone is not enough as the factor for experiential learning. However, if the internet is used to support new experiential learning in real life, then the user can create a further outstanding leap in learning outcomes.

"1000 times we watch cooking games will not become chefs. How to know the taste is salty, remember it's sweet if you have never tasted it ... So the game [cooking in simulation] is only for knowledge, huh. You have not yet felt broken when you fail and how it feels happy when successful. Even though it might hurt when playing, it fails, but there someone learns to recognize the strengths of others. That will not be felt only through game simulations ... So learning is a process, not just an outcome, if in the field of food science, salty, sweet, bitter, it must be tasted. But with technology, it's easy ...-G1, 60

Using the experiential learning cycle, students could gain goals on hands-on activity through comprehending step-by-step guidelines that furnish possibilities for reflection, conceptualization, and experimentation on the new standards and skills [16].

\section{H. Privacy}

The participants talked about user's privacy in cyberspace as an awareness of the importance of maintaining personal security and confidentiality of particular essential identities and prioritizing family private quality time. The participants noticed that not all moments need to be shared in public spaces (e.g., social media) on the internet for fear that it would imperil the privacy and well-being of children or family. 


\begin{abstract}
"The more mature I am about using social media. I feel that my family is not something that should be published just like that. Only important points, in my opinion, need to be published...I want to share with them how dangerous we are currently updating our family, ourselves, and our family's social media. "- G4, 7.

"[Parent's should supervise] without jeopardizing the privacy of our children, especially teenagers, if they really concern about privacy it seems like they will angry [if parent take peek at the history content access without their consent], surely, later on, they must erase the history" - G4, 73
\end{abstract}

Digital monitoring strategies have proven to be useful for preventing children from disclosing inappropriate personal information in cyberspace [17]. Active digital monitoring and parent internet participation consistently diminish the risk of publishing personal information on the website. The more children get older, the greater the tendency to share personal information through social media [18]. It is required to adjust the digital monitoring strategy to fit the child's development.

\section{Neuroscience and Sociology perspective}

The role of peer in digital engagement activities includes concerns about getting any friends, especially for teenagers. The participants also talked about digital engagement from the perspective of Neuroscience, in particular, about the growth of a child's brain. The previous studies in Neuroscience related to the use of technology have been discussed on how social media and the internet can influence social cognitive processes and the neural systems [19], [20]. The perspective of Sociology talked on focused group discussion was about the stages of children socialization in the family that occurred in response to new media use.

\section{CONCLUSION}

Digital monitoring strategies were including openness, restriction, participatory, storytelling and discussion, and structuring media locations. The study also suggested that contextual digital literacy was essential for socialization to the family members. The contribution of this research to digital monitoring theories is the exploration of the participants' contextual experiences. This study has limitations due to only one primary source of data collection (focussed group discussion), and these results may only be relevant to the criteria of participants in this study. Further research may be gaining more insight into investigating how this specific experience is related to family relational involvement. It would be interesting to construct parental monitoring in the Indonesian context.

\section{REFERENCES}

M. Prensky, "Digital Natives,Digital Immigrants Part 1," Horiz. vol. 9, no. 5, pp. 1-6, 2001, doi: 10.1108/10748121211256810.
Commun. Theory, vol. 21, pp. 323-343, 2011, doi: 10.1111/j.1468-2885.2011.01391.x.

[3] A. Reginasari and T. Afiatin, "Pengasuhan digital dan inkongruensi pengalaman di media sosial antara remaja dan orang tua," in Temu Ilmiah Nasional XI Ikatan Psikologi Perkembangan Indonesia, 2019, pp. 71-85.

[4] P. Nikken, "Implications of low or high media use among parents for young children's media use," Cyberpsychology, vol. 11, no. 3 Special Issue, 2017, doi: 10.5817/CP2017-3-1.

[5] R. Svensson, "Gender differences in adolescent drug use: The impact of parental monitoring and peer deviance," Youth Soc., vol. 34, no. 3, pp. 300-329, 2003, doi: 10.1177/0044118X02250095.

[6] T. J. Dishion and R. J. Mcmahon, "Parental monitoring and the prevention of child and adolescent problem behavior: A conceptual and empirical formulation," Clin. Child Fam. Psychol., vol. 1, no. 1, pp. 61-75, 1998.

[7] H. Stattin and M. Kerr, "Parental monitoring: A reinterpretation," Child Dev., vol. 71, no. 4, pp. 1072-1085, 2000.

[8] P. M. Valkenburg, M. Krcmar, A. L. Peeters, and N. M. Marseille, "Developing a scale to assess three styles of television mediation: 'Instructive mediation,' 'restrictive mediation,' and 'social coviewing,"' J. Broadcast. Electron. Media, vol. 43, no. 1, pp. 52-66, 1999, doi: 10.1080/08838159909364474.

[9] S. Livingstone and E. J. Helsper, "Parental mediation of children's internet use," J. Broadcast. Electron. Media, vol. 52, no. 4 , pp. $581-599,2008$.

[10] P. M. Valkenburg, J. T. Piotrowski, and J. Hermanns, "Developing and validating the perceived parental media mediation Scale: A self-determination Perspective," Hum. Commun. Res., vol. 39, pp. 445-469, 2013, doi: 10.1111/hcre.12010

[11] J. Beneke, G. Silverstone, A. Woods, and G. Schneider, "The influence of the youth on their parents' purchasing decisions of high-technology products," vol. 5, no. 10, pp. 3807-3812, 2011, doi: $10.5897 /$ AJBM10.359.

[12] D. A. Kolb, Experiential Learning. Englewood Cliffs, New Jersey: Prentice-Hall, Inc, 1984

[13] H. Y. Sung, G. J. Hwang, C. J. Lin, and T. W. Hong, "Experiencing the Analects of Confucius: An experiential gamebased learning approach to promoting students' motivation and conception of learning," Comput. Educ., vol. 110, pp. 143-153, 2017, doi: 10.1016/j.compedu.2017.03.014.

[14] E. M. Duvall, Marriage and family development. New York: J.B. Lippincott Company., 1977.

[15] A. Strauss and J. Corbin, Basics of qualitative research: Techniques and procedures for developing grounded theory, 2nd ed. London: Sage Publications, 1998.

[16] A. Konak, T. K. Clark, and M. Nasereddin, "Using Kolb's Experiential Learning Cycle to improve student learning in virtual computer laboratories," Comput. Educ., vol. 72, pp. 1122, 2014, doi: 10.1016/j.compedu.2013.10.013.

[17] M. O. Lwin, A. J. . S. Stanaland, and A. D. Miyazaki, "Protecting children's privacy online: How parental mediation strategies affect website safeguard effectiveness," J. Retail., vol. 84, no. 2, pp. 205-217, 2008, doi: 10.1016/j.jretai.2008.04.004.

[18] Y. Ji, G. Wang, Q. Zhang, and Z. Zhu, "Online social networking behaviors among Chinese younger and older adolescent: The influences of age, gender, personality, and attachment styles," Comput. Human Behav., vol. 41, pp. 393-402, 2014, doi: 10.1016/j.chb.2014.08.011

[19] D. Meshi, D. I. Tamir, and H. R. Heekeren, "The emerging neuroscience of social media," Trends Cogn. Sci., vol. 19, no. 12, pp. 771-782, 2015, doi: 10.1016/j.tics.2015.09.004.

[20] J. Sharit, S. J. Czaja, S. Nair, and C. C. Lee, "Effects of age, speech rate, and environmental support in using telephone voice menu systems," Hum. Factors, vol. 42, no. 2, pp. 234-251, 2003. 